\title{
Fractures of the proximal femur in the elderly in a sub-Saharan country
}

\author{
Ferdinand N. Mebouinz*, Joseph D. Diouf, Jean C. Sane, Souleymane Diao, \\ Amadou Kasse, Mouhamadou Habib S.
}

Department of Surgery, Orthopaedic Trauma, Idrissa Pouye Hospital, Cheikh Anta Diop University, Dakar, Senegal

Received: 12 November 2020

Accepted: 15 December 2020

\author{
*Correspondence: \\ Dr. Ferdinand N. Mebouinz, \\ E-mail: ferdinandmebouinz@gmail.com
}

Copyright: () the author(s), publisher and licensee Medip Academy. This is an open-access article distributed under the terms of the Creative Commons Attribution Non-Commercial License, which permits unrestricted non-commercial use, distribution, and reproduction in any medium, provided the original work is properly cited.

\section{ABSTRACT}

Background: The aim of this study was to describe the epidemiological, radiographic and therapeutic profile of the fractures of the proximal femur in the elderly in a sub-Saharan country.

Methods: A retrospective longitudinal study was carried out at the orthopedic trauma department of Idrissa Pouye Hospital in Senegal. Sixty-six patients recruited were aged at least 90 years; and treated for proximal femur fracture between 2008 and 2017.

Results: The median age of the patients was 91 years (90-107). Females represented 54.5\%. The fracture was located in the right $65.2 \%$. Femoral neck fractures were 53\% predominant with $94.3 \%$ type IV according to Garden's classification. Concerning the 31 patients with a pertrochanteric fractures, $61.3 \%$ were stable and $38.7 \%$ unstable. The time taken for seeking hospital care was an average of 5.8 \pm 9.7 days. All patients had a preoperative anesthesic score less than 4 according to the American society of anesthesiologists (ASA). The therapeutic indication was functional in $15.1 \%$ of cases, surgical by internal fixation in $39.2 \%$ and by arthroplasty in $45.7 \%$ of cases. Pertrochanteric fractures were managed by a dynamic hip screw (DHS) in $68.2 \%$ and by gamma nail in $18.2 \%$. Femoral neck fractures were managed by Moore's arthroplasty in $93.3 \%$ and by bipolar hip prothesis (BHP) in $6.7 \%$.

Conclusions: Fractures of the proximal femur represent a growing problem in sub-Saharan Africa. For patients above 90 years, the management remains essentially surgical by internal fixation in pertrochanteric fractures or by arthroplasty in cervical fractures.

Keywords: Fractures, Proximal femur, Elderly, Sub-Saharan, Epidemiology

\section{INTRODUCTION}

Fractures of the proximal femur (FPF) represent the leading cause of admission in trauma services worldwide. It is estimated that in 2050 , there would be 10 million cases; against 1.6 million only in $1950 .{ }^{1}$ The incidence increases exponentially with age, reaching a peak between 90 to 95 years; women being the most affected (70 to $80 \%) .^{2}$ It is a real public health problem worldwide, mainly in North America and Europe due to the aging of the population. ${ }^{2}$ With an average annual growth rate, several authors are already questioning the impact of the progressive aging of the population in sub-Saharan Africa on health systems. ${ }^{3,4}$ This study aims to describe the epidemiological, radiographic and therapeutic profile of proximal femur fractures in the elderly.

\section{METHODS}

\section{Study design and participants}

We carried out a retrospective longitudinal study on 66 patients aged 90 and over, hospitalized and treated for a fracture of the proximal femur between 2008 and 2017 in the orthopedics and trauma department of Idrissa Pouye Hospital. We conducted a census from the electronic register from the electronic register of hospitalizations. The files obtained from the archives were analyzed. We 
excluded from our analysis patients with non-union of the cervix and pertrochanteric.

\section{Data collection}

The data collected included age, sex, date of accident, circumstances and mechanism of injury. We also collected data on previous comorbidities, geriatric profile, radiographic classifications of femoral neck fractures according to Garden and pertrochanteric according to Ender, ASA risk. And other variables such as the systolic ejection function, the hemoglobin level, the history of rhythm or conduction disorders, the type of anesthesia, The time taken for seeking hospital care, initial traditional care, waiting at home for an intervention, length of hospitalization, the definitive treatment used, the surgical approach and decubitus complications.

\section{Statistics}

The data were captured using Epi InfoTM software version 7.1.5.2 and $\mathrm{R}$ studio version 1.0.143 software ( $\mathrm{R}$ development core team, Vienna, Austria) were used for statistical analysis.

\section{RESULTS}

The median age of the patients was 91.0 years [IQR 90.094.0] with extremes of 90 and 107 years. Women were predominant $(54.5 \%)$. Direct mechanism was the most reported in all patients. It occurred as a result of a fall with landing on the hip. The right lower limb was involved in $65.2 \%$ of the cases (Table 1). Predominant cardiovascular and metabolic comorbidities found in patients were high blood pressure in $21.2 \%$, followed by diabetes in $12.1 \%$, chronic kidney disease in $10.6 \%$ and heart failure in $4.6 \%$. The geriatric syndromes found on admission were predominantly loss of autonomy in $54.5 \%$, followed by falls in $22.7 \%$, visual disturbances (13.6\%) (mainly cataract), sphincter continence disorders $(9.1 \%)$ (Table 2$)$. The hemoglobin level at admission was on average 10.8 $( \pm 1.8) \mathrm{g} / \mathrm{dl}, 69.6 \%$ of patients had anemia including $13.6 \%$ moderate and $1.5 \%$ severe. The mean systolic ejection function was $65.9 \%$ with impairment in $18.2 \%$ of patients. On the electrocardiographic recordings, a rhythm disturbance and a conduction disorder were noted respectively in $30.4 \%$ and $53.6 \%$ of the patients.

There was a predominance of femoral neck fractures $(53 \%$ of cases). Type IV of Garden's classification of femoral neck fractures was mainly represented (94.3\%). Pertrochanteric fractures represented $47 \%$ of cases, mainly of type III from Ender (45.2\%) followed by type IV (22.6\%). The time taken for seeking hospital care was on average $5.8( \pm 9.7)$ days; with a median time of one day. In $26.7 \%$ of cases, there was a notion of traditional care for fractures increasing the time taken for hospital care. The therapeutic indication was functional in $14.1 \%$, surgical by internal fixation in $39.2 \%$ and by arthroplasty in $45.7 \%$ of the cases. Pertrochanteric fractures were managed by a dynamic hip screw (DHS) in $68.2 \%$ and by gamma nail in $18.2 \%$. The use of dynamic condylar screw (DCS), orthofix fixator and plate blade was noted in 3 cases. Fractures of the femoral neck were treated by a monobloc arthoplasty of Moore in $93.3 \%$ and intermediate by a bipolar hip prothesis (BHP) in $6.7 \%$ of the cases. The Hardinge way was the main way in $96.7 \%$.

Surgical intervention in patients with a pertrochanteric

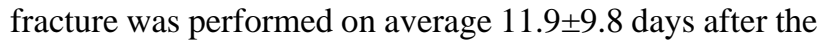
trauma, while for femoral neck fractures was performed on average $19.1 \pm 15.1$ days after the trauma with a significant difference (Table 3).

Table 1: General admission characteristics of elderly patients with a fracture of the proximal femur. Idrissa Pouye Hospital, Senegal, 2008-2017.

\begin{tabular}{|lll|}
\hline Characteristics & $(\mathbf{N = 6 6 )}$ & $\begin{array}{l}\text { Frequency } \\
(\%)\end{array}$ \\
\hline Age (years), mean (SD) & 92.6 & $(3.6)$ \\
\hline Age (years), med (Q1-Q3) & 91.0 & $(90.0-94.0)$ \\
\hline Sex & & \\
\hline Female & 36 & 54.5 \\
\hline Male & 30 & 45.5 \\
\hline Type of accident (n=65) & & \\
\hline Domestic accident (fall) & 65 & 100.0 \\
\hline Side reach & & \\
\hline Right & 43 & 65.2 \\
\hline Left & 23 & 34.8 \\
\hline
\end{tabular}

$\mathrm{n}=$ staff having the information provided

Table 2: Geriatric syndromes in elderly patients with a fracture of the proximal end of the femur. Idrissa Pouye Hospital, Senegal, 2008-2017.

\begin{tabular}{|lcc|}
\hline Syndromes & $(\mathbf{N}=66)$ & $\begin{array}{l}\text { Frequency } \\
(\%)\end{array}$ \\
\hline Autonomy loss & 36 & 54.5 \\
\hline Previous fall & 15 & 22.7 \\
\hline Hearing loss (n=65) & 1 & 1.5 \\
\hline Eyesight disorder & 9 & 13.6 \\
\hline Continence disorder & 6 & 9.1 \\
\hline Dementia syndrome & 1 & 1.5 \\
\hline $\begin{array}{l}\text { Confusional syndrome } \\
\text { (n=65) }\end{array}$ & 4 & 6.2 \\
\hline Regressive syndrome (n=65) & 0 & 0 \\
\hline Presence of pressure sores & 0 & 0 \\
\hline General ill health & 3 & 4.5 \\
\hline
\end{tabular}

$\mathrm{n}=$ staff having the information provided

Morbid complications related to decubitus occurred between the trauma and the verticalization of the patients. They were mainly represented by muscular atrophy at $49.2 \%$, bedsores (heels and buttocks) at $43.8 \%$, constipation at $36.9 \%$, urinary tract infections at $21.9 \%$ and decompensation of pre-existing tares in $8 \%$ of cases (Table 4). 
Table 3: Therapeutic aspects of elderly patients with a fracture of the proximal end of the femur. Idrissa Pouye Hospital, Senegal, 2008-2017.

\begin{tabular}{|c|c|c|}
\hline Therapeutic aspects & $(\mathrm{N}=66)$ & Frequency $(\%)$ \\
\hline Time taken for seeking hospital care (days), mean (SD) & 5.8 & 9.7 \\
\hline Time taken for seeking hospital care (days), med (Q1-Q3) & 1.0 & $1.0-6.7$ \\
\hline Waiting for home intervention $(n=66)$ & 15 & 22.7 \\
\hline Beginning of traditional care $(n=15)$ & 4 & 26.7 \\
\hline \multicolumn{3}{|l|}{ ASA score } \\
\hline ASA 1 & 21 & 31.8 \\
\hline ASA 2 & 39 & 59.1 \\
\hline ASA 3 & 6 & 9.1 \\
\hline \multicolumn{3}{|l|}{ Anesthesia $(\mathrm{n}=56)$} \\
\hline General anesthesia & 10 & 17.8 \\
\hline Locoregionale anesthesia & 46 & 82.2 \\
\hline Functional treatment & 9 & 14.1 \\
\hline Osteosynthesis $(\mathrm{n}=25)$ & 25 & 39.1 \\
\hline \multicolumn{3}{|l|}{ Indications } \\
\hline Gamma nail & 4 & 18.2 \\
\hline DCS & 1 & 4.5 \\
\hline DHS & 15 & 68.2 \\
\hline External fixation & 1 & 4.5 \\
\hline Plate blate & 1 & 4.5 \\
\hline Arthroplasty (n=30) & 30 & 46.9 \\
\hline \multicolumn{3}{|l|}{ Type arthroplasty } \\
\hline Moore & 28 & 93.3 \\
\hline Bipolar hip prosthesis & 2 & 6.7 \\
\hline \multicolumn{3}{|l|}{ Approach arthroplasty } \\
\hline Hardinge & 29 & 96.7 \\
\hline Moore & 1 & 3.3 \\
\hline Duration of hospitalization (days), mean (SD), $(n=64)$ & 13.3 & $(10.3)$ \\
\hline \multicolumn{3}{|l|}{ Intervention delay (days), moy (SD), $(\mathrm{n}=64)$} \\
\hline Neck fracture & 19.1 & 15.1 \\
\hline Pertrochanteric fracture & 11.9 & 9.8 \\
\hline
\end{tabular}

$\mathrm{n}=$ staff having the information provided

Table 4: Decubitus complications in elderly patients with a fracture of the proximal femur. Idrissa Pouye Hospital, Senegal, 2008-2017.

\begin{tabular}{|lrc|}
\hline Complications & $(\mathbf{N}=\mathbf{6 5})$ & Frequency (\%) \\
\hline Orthostatic hypotension & 3 & 4.6 \\
\hline Inhalation pneumonia & 1 & 1.5 \\
\hline Thromboembolic diseases & 2 & 3.1 \\
\hline Muscular atrophy & 32 & 49.2 \\
\hline Proprioception disorder & 2 & 3.1 \\
\hline Constipation & 24 & 36.9 \\
\hline Urinary tract infections (n=64) & 14 & 21.9 \\
\hline Bedsores (n=64) & 28 & 43.8 \\
\hline Confusion, depression, dementia, refusal of care $(\mathbf{n}=\mathbf{6 4})$ & 5 & 7.8 \\
\hline Decompensation of cardiovascular or metabolic tare & & 3.2 \\
\hline Hypertension & 2 & 4.8 \\
\hline Cardiac failure & 3 & \\
\hline
\end{tabular}




\section{DISCUSSION}

In our series, the average age was 92.6 years, approaching the peak occurrence of FPF according to Cooper in Great Britain and Dhanwal et al in India. ${ }^{2,5}$ The fall on the same level with a direct shock mechanism on the hip was found in all cases, a result similar to that of Wehren et al and Melton. ${ }^{6,7}$ This low energy mechanism has been described as being sufficient to induce fracture lesions of the femoral neck and the trochanteric mass in the elderly. This fragility of the senile proximal femur can be explained by the decrease in bone mass, architectural abnormalities, matrix or mineralization of the bone and the presence of microfractures. ${ }^{6,7}$ The predominance of the female sex is found in almost all studies. Our 55\% is close to $55.3 \%$ for El Maghraoui et al in Morocco. ${ }^{8}$ In other studies, this predominance is more important; $65.2 \%$ for Karademir et al in 2015; $82 \%$ for Petros et al in 2017..$^{9,10}$ Melton explains this trend by the decrease in bone density of the cervicotrochanteric region over time by an average of $53 \%$ in women and $35 \%$ in the man. ${ }^{7}$ Wehren, on the other hand, believes that in older women, women fall more than men due to greater muscle weakness; which may explain the fact that the sex ratio is in their favor. ${ }^{6}$ The fracture was mainly on the right in this study $(65 \%)$. A similar proportion to that of Bayray et al in Ethiopia which showed in 2012 that the right side was affected in $62 \%$ of cases. 11 Like Meessen et al in 2014, this study found as comorbidities, cardiovascular and metabolic pathologies increased by high blood pressure, diabetes and chronic kidney disease. $^{12}$

The term geriatric syndrome has been used to describe common clinical situations in the elderly involving multiple organs that do not correspond to a specific pathology or group of pathologies. ${ }^{13}$ In this study, the analysis of geriatric syndromes in the year preceding the trauma made it possible to find a proportion of loss of autonomy in $54.5 \%$, followed by previous experiences of falls in $22.7 \%$, disorders of eyesight at $13.6 \%$ (mainly cataracts), sphincter continence disorders at $9.1 \%$. According to Wehren et al, all of these geriatric problems should be managed because they represent risk factors for morbid falls, causing and increasing the incidence of fractures of the proximal femur. ${ }^{6}$ Laurence et al identify some causes of these falls, namely muscle weakness, neurological gait disorders, confusion and self-medication; they argue that preventing these risks of falling significantly reduces the incidence of FPF. ${ }^{14}$ In our study, the frequency of previous fall experiences was $22.7 \%$; slightly higher than the $16.8 \%$ of Gonzalez-Lopez et al in 2014 in Mexico. ${ }^{15}$ In France, Dubois also found loss of autonomy, fall experiences, and vision problems as the main geriatric syndromes in the results of her thesis on the SAFES cohort (fragile aged subjects: evaluation and monitoring) in $2008 .{ }^{16}$

Femoral neck fractures represented 53\%; while pertrochanteric fractures represented $47 \%$. These results are similar to those of Graham et al who found $51 \%$ of intracapsular fractures and $49 \%$ of extracapsulars. ${ }^{17}$ In our series, $22.7 \%$ of patients waited for their intervention at home with an anti-rotation boot; this due to the lack of beds for admission. We noticed that this waiting period at home was associated with an increase in decubitus complications, an increase in the time of the surgical intervention and a preservation of the functional treatment. After the onset of the trauma, 26.7\% had initiated care for a bone repairer, which increased the time for hospital care. Several authors have shown that the traditional management of closed fractures occupies a preponderant place in our context. ${ }^{18,19}$

In this study, 31.8\% were ASA1, and 69.2\% ASA 2 and 3. This made it possible to perform surgical procedures in more than $85 \%$ of the cases. In our series, the treatment was functional in $14 \%$ of the cases, and surgical in $86 \%$. The management of intracapsular fractures has interested several authors. Regarding the functional treatment of nondisplaced intracapsular fractures, representing 5.3\% in our study; Raaymaker et al in 1991, found a consolidation rate of $86 \% .^{20}$ Similarly, concerning functional treatment, Cserhati et al reported the occurrence of $20 \%$ secondary displacements. ${ }^{21}$ In our series, the significant proportion of functional treatment can be explained by the delay in hospital management and ASA state of our patients which was 2 to 3 in $69.2 \%$. In our study, Garden classification type 4 displaced intracapsular fractures accounted for $94.7 \%$ of cervical fractures and $93.3 \%$ of them had a Moore's prosthesis. In England, the management of displaced intracapsular fractures is surgical in almost $98 \%$ according to the national hip fracture database annual report in 2014. ${ }^{22}$ In that report, instead of a Moore prosthesis, an intermediate prosthesis was used in $91 \%$ of cases. This difference in choice of prosthetic implants can be explained by the fact that in their study, the age group was 60 to over 110 years while ours was 90 and over. On the other hand, its affordable cost is more affordable. The Moore's prosthesis is more indicated in people with a fairly low life expectancy, in view of its complications of cotyloiditis and periprosthetic fractures estimated at $14 \%$ at two years by McGraw et al in 2013. ${ }^{23}$

In our study, pertrochanteric fractures were stable in $61.3 \%$ (types 1, 2 and 3 of Ender), and unstable in $38.7 \%$ (types 4, 5, 6, 7 and 8 of Ender). They were treated by DHS in $68.2 \%$ of the cases, by gamma nail in $18.2 \%$. The low proportion of gamma nail indications in these fractures was due to the fact that they began to be used quite late compared to DHS in the service. Consolidation was achieved in all cases. Regarding stable pertrochanteric fractures, in 2017 Sharma et al in Brazil found no differences in the occurrence of early and late complications depending on the use of DHS or the gamma nail. ${ }^{24}$ Still, restoration of function and autonomy was significantly earlier, 3 months, when a gamma nail was used. In fact, according to Steinberg et al the gamma nail has the advantage of bringing greater biomechanical stability to mounting, on an osteoporotic bone, by reducing the distance between the center of the hip and the implant, 
this which allows a faster resumption of walking. In unstable pertrochanteric fractures, surgery is still the treatment of choice for early mobilization and restoration of previous autonomy. ${ }^{25}$ In 2001, Kim et al found a consolidation failure rate of $50 \%$ in 178 unstable pertrochanteric fractures on osteoporotic bone, operated by DHS. They then recommended using a gamma nail in these cases. ${ }^{26}$

The average time for surgery in our series was $19.1 \pm 15.1$ days (3-34 days) for cervical fractures and 11.9 \pm 9.8 days for pertrochanteric patients with a statistically significant difference. This average intervention time was too long compared to those found in the literature, which averaged 2 days in $61.7 \%$ according to Requant et al in Spain. ${ }^{27} \mathrm{We}$ were unable to find similar studies in sub-Saharan Africa. The identified factors explaining this significant delay in surgical intervention were traditional management, lack of knowledge of the occasional trauma by the family, cost of management, associated comorbidities, ASA level.

\section{CONCLUSION}

Fractures of the proximal femur are a growing problem in sub-Saharan Africa. For patients above 90 years of age, they result in high morbidity linked to the loss of autonomy that they cause. The elderly presents modifiable geriatric syndromes which precede the fall causing fractures of the proximal femur. With the gradual ageing of the subSaharan population, the elderly with fractures of the proximal femur will be more and more demanding of orthopedic surgery. Management should be as early as possible. Measures to prevent their occurrence should interest health policies given the gradual aging of the subSaharan population.

\section{ACKNOWLEDGEMENTS}

Authors are grateful to all participants and physicians who participated in this research.

Funding: No funding sources

Conflict of interest: None declared

Ethical approval: The study was approved by the institutional ethics committee

\section{REFERENCES}

1. Féron JM, Thomas T, Roux C, Puget J. Osteoporosis and the orthopaedic surgeon in 2007. Rev Chir Orthop Reparatrice Appar Mot. 2008;94(6):99-107.

2. Cooper C, Campion G, Melton LJ. Hip fractures in the elderly: a world-wide projection. Osteoporos Int J Establ Result Coop Eur Found Osteoporos Natl Osteoporos Found USA. 1992;2(6):285-9.

3. Berthe A, Berthé-Sanou L, Konaté B, Hien H, Tou F, Drabo $\mathrm{M}$, et al. Les personnes âgées en Afrique subsaharienne: une population vulnérable, trop souvent négligée dans les politiques publiques, The elderly in sub-Saharan Africa: a vulnerable population often ignored in public policy. Santé Publique. 2013;25(3):367-71.

4. Schoumaker B. Le vieillissement en Afrique subsaharienne. Espace Popul Sociétés. 2000;18(3):379-90.

5. Dhanwal DK, Siwach R, Dixit V, Mithal A, Jameson $\mathrm{K}$, Cooper $\mathrm{C}$. Incidence of hip fracture in Rohtak district, North India. Arch Osteoporos. 2013;8:135.

6. Wehren L, Magaziner J. Prevention of falls in management of fractures in severely osteoporotic bone. London : Springer-Verlag. 2000;333-52.

7. Melton LJ. Hip fractures: a worldwide problem today and tomorrow. Bone. 1993;14(1):1-8.

8. El Maghraoui A, Koumba BA, Jroundi I, Achemlal L, Bezza A, Tazi MA. Epidemiology of hip fractures in 2002 in Rabat, Morocco. Osteoporos Int J Establ Result Coop Eur Found Osteoporos Natl Osteoporos Found USA. 2005;16(6):597-602.

9. Karademir G, Bilgin Y, Erşen A, Polat G, Buget MI, Demirel M, et al. Hip fractures in patients older than 75 years old: Retrospective analysis for prognostic factors. Int J Surg Lond Engl. 2015;24(A):101-4.

10. Petros RSB, Ferreira PEV, Petros RSB. Influence of proximal femur fractures in the autonomy and mortality of elderly patients submitted to osteosynthesis with cephalomedullary nail. Rev Bras Ortop. 2017;52(1):57-62.

11. Bayray A, Enquselassie F, Gebreegziabher Z. Magnitude and pattern of osteoporotic fractures among adults in Tigiray, Ethiopia; a retrospective hospital based study. Ethiop Med J. 2012;50(4):297305.

12. Meessen JMTA, Pisani S, Gambino ML, Bonarrigo D, van Schoor NM, Fozzato S, et al. Assessment of mortality risk in elderly patients after proximal femoral fracture. Orthopedics. 2014;37(2):194-200.

13. Inouye SK, Studenski S, Tinetti ME, Kuchel GA. Geriatric syndromes: clinical, research, and policy implications of a core geriatric concept. J Am Geriatr Soc. 2007;55(5):780-91.

14. Rubenstein LZ. Falls in older people: epidemiology, risk factors and strategies for prevention. Age Ageing. 2006;35(2):37-41.

15. González-López AM, Vázquez-Cruz E, RomeroMedina JL, Gutiérrez-Gabriel I, Montiel-Jarquín AJ, Salvatori J, et al. Geriatric syndromes in patients with a non-recent hip fracture seen at a primary health care unit. Acta Ortop Mex. 2014;28(5):287-90.

16. Desbois A. Pathologies et complications de l'immobilisation associées à la sévérité du déclin moteur chez les patients âgés de plus de 75 ans lors d'une hospitalisation non programmée dans un service de médecine: à partir de la cohorte SAFES. 2008.

17. Graham SK, Martin J P, Glyn AP. Mortality and morbidity after hip fractures. BMJ. 1993;1248-50.

18. Mensah E, Tidjani IF, Chigblo P, Lawson E, Ndeffo $\mathrm{K}$, Hans-Moevi Akué A. Aspects épidémiologiques et lésionnels des complications du traitement traditionnel des fractures de membres à Parakou 
(Bénin). Rev Chir Orthopédique Traumatol. 2017;103(3):330-4.

19. Lamah L, Abalo A, Dansokho AV, Diakite SK, Dieme CB, Kinkpe CV, et al. Complications du traitement traditionnel des fractures : à propos de 36 cas, au service d'orthopédie Aristide Le Dantec de Dakar. J Rech Sci L’Université Lomé [Internet]. 2009;11(2). Available at: https://www.ajol.info/index.php/jrsul/article/view/5 6933. Accessed on: 06 October 2018.

20. Raaymakers E, Marti R. Non-operative treatment of impacted femoral neck fractures. A prospective study of 170 cases. J Bone Joint Surg Br. 1991;73$\mathrm{B}(6): 950-4$.

21. Cserháti P, Kazár G, Manninger J, Fekete K, Frenyó S. Non-operative or operative treatment for undisplaced femoral neck fractures: a comparative study of 122 non-operative and 125 operatively treated cases. Injury. 1996;27(8):583-8.

22. Physicians RC of. National Hip Fracture Database Annual Report 2014. In RCP London. 2014.

23. McGraw IWW, Spence SC, Baird EJ, Eckhardt SM, Ayana GE. Incidence of periprosthetic fractures after hip hemiarthroplasty: Are uncemented prostheses unsafe? Injury. 2013;44(12):1945-8.
24. Sharma A, Sethi A, Sharma S. Treatment of stable intertrochanteric fractures of the femur with proximal femoral nail versus dynamic hip screw: a comparative study. Rev Bras Ortop. 2017;53(4):47781.

25. Steinberg EL, Blumberg N, Dekel S. The fixion proximal femur nailing system: biomechanical properties of the nail and a cadaveric study. J Biomech. 2005;38(1):63-8.

26. Kim WY, Han CH, Park JI, Kim JY. Failure of intertrochanteric fracture fixation with a dynamic hip screw in relation to pre-operative fracture stability and osteoporosis. Int Orthop. 2001;25(6):360-2.

27. Reguant F, Bosch J, Montesinos J, Arnau A, Ruiz C, Esquius P. Prognostic factors for mortality in elderly patients with hip fracture. Rev Esp Anestesiol Reanim. 2012;59(6):289-98.

Cite this article as: Mebouinz FN, Diouf JD, Sane JC, Diao S, Kasse A, Mouhamadou HS. Fractures of the proximal femur in the elderly in a sub-Saharan country. Int J Res Orthop 2020;7:19-24. 